\title{
O ensino de Ciências como elemento integrante da formação cidadã: mapeamento de teses e dissertações (1997-2018)
}

\author{
La enseñanza de las ciencias como elemento integral de la formación \\ ciudadana: mapeo de tesis y disertaciones (1997-2018)
}

\section{The teaching of sciences as an participant element of citizen education: mapping of thesis and dissertations (1997-2018)}

\author{
Me. Wanderson Diogo Andrade da Silva ${ }^{1}$ \\ Dra. Claudia Christina Bravo e Sá Carneiro
}

\begin{abstract}
Resumo
Tendo como condução metodológica o Estado da Questão, este artigo construiu um mapeamento de pesquisas que discutem o ensino de Ciências como elemento integrante da formação cidadã sob o viés do saber não disciplinado, oriundas da Biblioteca Brasileira Digital de Teses e Dissertações entre o período de 1997 a 2018. Foram selecionadas oito produções, sendo a maioria fruto de teses ou dissertações em Ensino de Ciências desenvolvidas na última década, indicando a necessidade de ampliação dessa discussão numa perspectiva interdisciplinar para a superação do ensino acrítico e dissociado da relação ciência-sociedade-ambiente.
\end{abstract}

Palavras-Chave: Cidadania; Ensino de Ciências; Estado da Questão.

\section{Resumen}

Utilizando el Estado de la pregunta como guía metodológica, este artículo construyó un mapeo de investigaciones que discuten la enseñanza de las ciencias como un elemento integral de la educación ciudadana bajo el sesgo del conocimiento no disciplinado, de la Biblioteca Digital Brasileña de Tesis y Disertaciones entre 1997 hasta 2018. Se seleccionaron ocho producciones, la mayoría el resultado de tesis o disertación en Enseñanza de las Ciencias desarrollada en la última década, lo que indica la necesidad de expandir esta discusión en una perspectiva interdisciplinaria para superar la enseñanza no crítica y disociada de la relación cienciasociedad-medio ambiente.

Palabras claves: Ciudadanía; Enseñanza de las ciencias; Estado de la cuestión.

\begin{abstract}
With the State of the Question as methodological guidance, this article constructed a mapping of research that approach Science teaching as an integral element of citizen education under the bias of non-disciplined knowledge, based on the Brazilian Digital Library of Theses and Dissertations and the National Research Meetings in Science Education, from 1997 to 2018. Eight productions were selected, most of them the result of a thesis or dissertation in Science teaching developed in the last decade, indicating the need to expand this discussion in an interdisciplinary perspective to overcome uncritical teaching and dissociated from the sciencesociety-environment relationship.
\end{abstract}

Keywords: Citizenship; Science teaching; State of the Question.

\footnotetext{
1 Mestre em Educação Brasileira; Universidade Federal do Ceará; Fortaleza, Ceará, Brasil; wandersondiogo@hotmail.com

2 Pós-doutorado em Educação; Universidade Federal do Ceará; Fortaleza, Ceará, Brasil; ccbcarneiro@hotmail.com
} 


\section{Introdução}

A divisão do sistema educacional brasileiro, ao longo de sua história, emergiu como um mecanismo potencializador das desigualdades socioeducacionais ao conceber currículos distintos para a burguesia e para a classe trabalhadora. Enquanto para o primeiro tem-se um currículo diversificado e enriquecido culturalmente, destina-se para o segundo um currículo mínimo que, em suma, atua socialmente para dar atestados de frequência à população pobre (GADOTTI, 2006), inviabilizando uma educação de e com qualidade para todos e todas.

Aqui, entende-se que a classe trabalhadora não tem ingressado na escola, mas o contrário, a escola tem invadido a vida desses sujeitos, sobretudo em situação de desigualdade, assumindo o seu posicionamento enquanto instituição panóptica. Assim, surge a necessidade de uma educação que busque romper com práticas educativas (re)produtoras de um ensino com viés moralista e assistencialista que concebe o aluno como sujeito carente de outros costumes e saberes culturais que não condizem com sua realidade e suas necessidades.

Nesse cenário, o ensino de Ciências possibilita a introdução do aluno ao mundo do conhecimento científico e tecnológico utilizado para formar um senso crítico na luta pelos seus direitos, no cumprimento de seus deveres, na defesa do próximo e do meio ambiente (SILVA; CARNEIRO, 2019). Nessa visão, o ensino de Ciências deixa de ser reprodutor de informações e assume seu papel de formar cidadãos conscientes. Portanto, a escola, enquanto instituição social, deve ser compreendida como um dos principais espaços de construção dessa formação ao conceber cada aluno e seus diferentes saberes culturais como sendo legítimos e relevantes.

Dessa forma, em meio a tais apontamentos, surge o seguinte questionamento: de que forma o ensino de Ciências pode se articular à formação cidadã no currículo escolar visando subsidiar o desenvolvimento dos alunos? Um dos caminhos a serem percorridos a fim de responder esse questionamento é o reconhecimento de que o ensino de Ciências não deve ser posto de forma disciplinar, isto é, centrado apenas em um componente curricular, pois abordagens unicamente disciplinares podem gerar explorações a-históricas da construção do conhecimento científico e tecnológico, culminando no surgimento de barreiras epistemológicas e segmentação do saber. Assim, uma vez que este estudo parte do entendimento de que quanto mais disciplinado for o ensino de Ciências, menores serão suas contribuições para a formação cidadã, coaduna-se com Chassot (2012) quanto à necessidade 
de um ensino mais in-disciplinado ${ }^{3}$ que vise oportunizar aos alunos uma formação científicacidadã significativa.

Entendemos, dessa forma, que trabalhar a interdisciplinaridade pressupõe um diálogo e interação desses conhecimentos que fogem da estrutura linear e hierarquizada do saber/fazer docente. $\mathrm{O}$ ensino de Ciências deve se tornar um elemento de integração na formação cidadã, não excluindo a "dimensão social, cultural na abordagem de questões e de situações comuns e busque, no cotidiano dos alunos, informações/elementos a fim de concretizar uma educação para a cidadania" (SILVA, 2000, p. 181, grifos da autora).

Partindo desse entendimento, o presente estudo, tendo como condução metodológica o Estado da Questão (EQ), tem como objetivo construir um mapeamento das pesquisas que enfatizam o ensino de Ciências como elemento integrante da formação cidadã oriundas da Biblioteca Digital Brasileira de Teses e Dissertações (BDTD).

\section{A construção metodológica do Estado da Questão}

Nos últimos anos, tem-se recorrido a abordagens metodológicas do tipo estado da arte, revisão de literatura e, mais recentemente, ao estado da questão (EQ) para agregar consistência teórico-metodológica aos estudos e, consequentemente, situar as contribuições que determinada produção trará ao campo científico, ao mesmo tempo em que se busca traçar um caminho de investigação até então inédito com base no que já foi explorado.

Tais abordagens, embora apresentem características em comum, fazendo com que sejam erroneamente compreendidas como uma só, dispõem de particularidades que lhes agregam diferentes sentidos, conforme destacam Nóbrega-Therrien e Therrien (2010). Para os referidos autores, o EQ se apresenta como importante aporte para trabalhos acadêmicos porque "conduz a identificar o que existe na ciência sobre o tema e, a partir daí, delimitar e definir que contribuição a realização do estudo pode trazer para a área científica" (p. 36). Diferencia-se da revisão de literatura e do estado da arte, por exemplo, tendo em vista que estes adentram mais na construção do referencial teórico das pesquisas, enquanto o " EQ traz contribuições que subsidiam todas as partes que compõem a investigação científica, como um todo" (p. 36).

\footnotetext{
${ }^{3} \mathrm{O}$ termo in-disciplinado é adotado aqui não no sentido de indisciplina escolar, mas no sentido de transgredir o ensino especializado, disciplinado, para uma prática pedagógica transdisciplinar (CHASSOT, 2011).
} 
Para além de identificar aspectos das pesquisas que abordem determinado tema, é preciso tecer uma articulação dos resultados encontrados para que estes não sejam apresentados de forma reducionista. Neste estudo, a elaboração do EQ se deu a partir da delimitação do cenário geográfico nacional em virtude da existência de cursos de formação inicial e continuada de professores de Ciências em todo o país, o que possibilita o surgimento de pesquisas sobre o ensino de Ciências como elemento integrante da formação cidadã em todo o território nacional.

Foi delimitado como campo para a busca ${ }^{4}$ a Biblioteca Digital Brasileira de Teses e Dissertações (BDTD), composta por 107 instituições superiores brasileiras de ensino e pesquisa, públicas e privadas. Como pesquisas oriundas de outros campos de busca não foram consideradas aqui, este estudo representa apenas um pequeno recorte de espaço e tempo, não saturando as informações teórico-metodológicas sobre o assunto.

Ainda que outros acontecimentos históricos tenham evidenciado a necessidade da formação cidadã na educação escolar, tais como a própria Constituição Federal de 1988, o recorte temporal aqui analisado corresponde ao período de 1997 a 2018 por adotar a lei $\mathrm{n}^{\circ}$ 9.394, de 20 de dezembro de 1996, que instituiu as Diretrizes e Bases da Educação Nacional (LDB), como marco histórico principal. Nesta lei infraconstitucional norteadora do sistema educacional brasileiro, também fica estabelecido como uma das finalidades da educação escolar a formação para a cidadania. Portanto, o recorte engloba pesquisas realizadas logo após sua promulgação.

\section{O percurso das buscas e o surgimento dos achados: quais pesquisas contemplam a questão?}

A busca pelas pesquisas que discutem a formação cidadã no ensino de Ciências ocorreu entre as produções dos programas de pós-graduação stricto sensu que compõem a BDTD $^{5}$, utilizando-se alguns descritores. Utilizou-se a ferramenta de busca avançada por permitir a combinação desses descritores com o auxílio do operador booleano AND, possibilitando maior rapidez e refinamento dos resultados que contemplavam, no mínimo, um desses descritores: i) Ensino de Ciências AND Formação Cidadã (Formação para a Cidadania); ii) Educação Científica AND Formação Cidadã (Formação para a Cidadania); e

\footnotetext{
${ }^{4}$ As buscas em ambos os campos foram realizadas em novembro de 2018.

5 http://bdtd.ibict.br
} 
iii) CTS (CTSA) AND Formação Cidadã (Formação para a Cidadania). As palavras dentro dos parênteses representam palavras cognatas utilizadas em algumas pesquisas e, portanto, também adotadas aqui.

Foram identificadas 453 teses e dissertações que contemplavam pelo menos um desses descritores em seus títulos. Após a leitura dos títulos, foram selecionadas 40 produções que abrangiam a temática, conforme apresentado na tabela 1 .

Tabela 1 - Quantitativo de publicações encontradas na BDTD (1997-2018)

\begin{tabular}{ccrc}
\hline Descritores & $\begin{array}{c}\text { Produções } \\
\text { encontradas }\end{array}$ & $\begin{array}{c}\text { Selecionadas } \\
\text { por título }\end{array}$ & $\begin{array}{c}\text { Selecionadas } \\
\text { pelo resumo }\end{array}$ \\
\hline $\begin{array}{c}\text { Ensino de Ciências AND Formação } \\
\text { Cidadã (Formação para a Cidadania) }\end{array}$ & 229 & 24 & 5 \\
$\begin{array}{c}\text { Educação Científica AND Formação } \\
\text { Cidadã (Formação para a Cidadania) }\end{array}$ & 169 & 8 & 1 \\
$\begin{array}{c}\text { CTS (CTSA) AND Formação Cidadã } \\
\text { (Formação para a Cidadania) }\end{array}$ & 55 & 8 & 2 \\
\hline Total & $\mathbf{4 5 3}$ & $\mathbf{4 0}$ & $\mathbf{8}$ \\
\hline
\end{tabular}

Na sequência, realizou-se a leitura dos resumos visando um maior refinamento das produções que, de fato, discutiam o ensino de Ciências na perspectiva da formação cidadã, sendo selecionadas apenas 8 que se integravam a proposta deste estudo. A tabela 2 apresenta a descrição das produções selecionadas em ordem cronológica.

Tabela 2 - Teses e Dissertações encontradas no site da BDTD (1997 - 2018)

\begin{tabular}{|c|c|}
\hline Produção/Autoria/Ano & $\begin{array}{l}\text { Programa de Pós- } \\
\text { Graduação/Instituição }\end{array}$ \\
\hline $\begin{array}{l}\text { Tese - Dilemas vividos por duas professoras da escola } \\
\text { pública ao ensinarem ciências em uma perspectiva de } \\
\text { formação para a cidadania (CAMARGO, 2010) }\end{array}$ & Educação/UFSCar \\
\hline $\begin{array}{l}\text { Dissertação - Alfabetização científica nos anos iniciais } \\
\text { do ensino fundamental na rede municipal de } \\
\text { Piranguçu/MG: formação e prática (SILVA, 2013) }\end{array}$ & $\begin{array}{l}\text { Ensino de Ciências } \\
\text { (Profissional)/UNIFEI }\end{array}$ \\
\hline $\begin{array}{l}\text { Dissertação - Ensino de Ciências na perspectiva CTS - } \\
\text { concepções e práticas escolares (OLIVEIRA, 2013) }\end{array}$ & $\begin{array}{l}\text { Ensino de Ciências Naturais } \\
\text { e Matemática/UFS }\end{array}$ \\
\hline $\begin{array}{l}\text { Tese - A formação de um professor de ciências } \\
\text { pesquisador a partir de seu saber/fazer pedagógico } \\
\text { (SILVA, 2014) }\end{array}$ & $\begin{array}{lll}\text { Educação em } & \text { Ciências: } \\
\text { Química da vida e } \\
\text { saúde/UFRGS }\end{array}$ \\
\hline $\begin{array}{l}\text { Dissertação - Análise interpretativa de relatos de } \\
\text { professores de Ciências sobre o tema cidadania } \\
\text { (MATIAS, 2014) }\end{array}$ & $\begin{array}{l}\text { Ensino, História e Filosofia } \\
\text { das Ciências e da } \\
\text { Matemática/ UFABC }\end{array}$ \\
\hline $\begin{array}{l}\text { Dissertação - Projetos temáticos e enfoque CTS na } \\
\text { educação básica: caracterização dos trabalhos } \\
\text { apresentados por autores brasileiros, espanhóis e } \\
\text { portugueses nos seminários ibero-americanos de CTS }\end{array}$ & $\begin{array}{l}\text { Ensino de Ciências } \\
\text { (Profissional)/UNIFEI }\end{array}$ \\
\hline
\end{tabular}


(GONÇALVES, 2014)

Dissertação - Ciências da natureza no Projovem Educação/UEFS

Urbano: discursos de um currículo inventado e praticado (SANTANA, 2015)

Dissertação - Desenvolvimento de uma matriz de Ensino de Ciências competências e habilidades para repensar o ensino de (Profissional)/UnB ciências pela perspectiva do ensino por investigação (VALDEZ, 2017)

As pesquisas selecionadas inicialmente para leitura do título e resumo, mas que não integram o EQ, foram descartadas por abordarem o ensino de Ciências sob a ótica do disciplinamento ao envolver apenas a Biologia, a Física ou a Química, por exemplo, não considerando o ensino de Ciências dentro do que aqui é defendido. Outras foram descartadas por não estarem disponíveis na íntegra no campo de busca, dificultando o acesso e leitura destas.

\section{Discutindo e significando as produções mapeadas}

As tabelas apresentadas anteriormente revelam um conjunto de informações importantes e necessárias para se compreender como a formação cidadã tem sido explorada nas pesquisas acadêmicas disponibilizadas no portal da BDTD. A quase totalidade das produções é fruto de pesquisas de mestrado, sendo três acadêmicos e três profissionais oriundos, em sua maioria, de programas em Ensino de Ciências. Encontrou-se apenas duas teses de doutorado, sendo uma em Educação e uma em Educação em Ciências, indicando que as discussões sobre a temática são incipientes nos cursos de doutorado, bem como nos programas de pós-graduação em Educação ou em áreas científicas específicas, como (Ensino de) Biologia, (Ensino de) Física ou (Ensino de) Química.

Nenhuma está vinculada à instituição de ensino superior (IES) privada, sustentando a defesa de "que, no Brasil, instituições privadas de ensino superior que se dedicam à pesquisa científica são raras exceções, ficando a produção de conhecimento científico a cargo principalmente das universidades públicas" (CHIARINI; VIEIRA, 2012, p. 118). Tal constatação reforça a importância das IES públicas na produção e promoção do conhecimento para a população brasileira, especialmente em tempos de ataque governamentais à educação, às universidades públicas e gratuitas, à ciência e à tecnologia brasileiras, conforme vivenciado no país nos últimos tempos.

Embora existam cursos de licenciatura na área de Ciências, bem como programas de pós-graduação stricto sensu na área da Educação ou de Ensino de Ciências em todas as 
regiões do país, verificou-se que nem todas possuem produções sobre a temática pesquisada. Há predomínio de produções na região Sudeste, sendo esta responsável por metade das produções analisadas. A região Nordeste possui duas produções, assim como as Regiões Centro-Oeste e Sul, sendo uma para cada. A Região Norte não apresenta registros, o que revela a baixíssima produção científica sobre esta temática no âmbito dos cursos de mestrado e doutorado no país.

Embora esses dados reflitam a realidade apenas da BDTD, não podendo ser generalizada, essa constatação não é novidade em se tratando da comparação entre as produções das regiões brasileiras, sobretudo Norte/Nordeste e Sul/Sudeste. Dentre outros motivos, considera-se que essa má distribuição geográfica entre as produções no campo pesquisado se dá pela consolidação deste campo nas regiões Sul/Sudeste, estando nas outras ainda em processo de expansão e consolidação com a criação dos cursos de mestrado e doutorado na área. Essa discussão é reforçada por Sidone, Haddad e Mena-Chalco (2016) ao investigarem a evolução da produção e das redes de colaboração científica em todas as regiões do Brasil, identificando "diferenças acentuadas entre as distribuições regionais da produção e as configurações espaciais das redes de cada área do conhecimento" (p. 15).

Quanto ao recorte temporal, ainda que a formação cidadã tenha sido instituída pela LDB em 1996, apenas recentemente as produções sobre o ensino de Ciências passaram a se debruçar sobre essa articulação necessária para a formação dos alunos da educação básica. Entre o período de 1997 a 2018 só foram encontradas produções através do EQ a partir de 2010 na BDTD, porém com descontinuidades, pois em 2008, 2012, 2016 e 2018 não há registros.

2013 e 2014 são os anos com maior produção sobre a temática na BDTD, resultando no reconhecimento da necessidade de expansão dessas discussões no meio acadêmico, pois "pensar a cidadania e o ensino de ciências na realidade implica desconstruirmos a ideia de uma sociedade já dada com uma ordem a priori, em que cada cidadão deve cooperar para o seu funcionamento" (PINHÃO; MARTINS, 2016, p. 26) a fim de que cada sujeito se emancipe e rompa as determinações do status quo. Esse cenário revela que as produções no campo pesquisado ainda pouco discutem o ensino de Ciências como elemento necessário para a formação cidadã, mesmo passado mais de duas décadas da promulgação da LDB, em 1996, tornando-se necessário e: 
importante discutir os diferentes significados e funções que se têm atribuído à educação científica com o intuito de levantar referenciais para estudos na área de currículo, filosofia e política educacional que visem analisar o papel da educação científica na formação do cidadão (SANTOS, 2007, p. 475).

Metodologicamente, as oito produções possuem abordagem qualitativa, porém duas não especificaram qual o tipo de estudo adotado. Quanto às demais, há estudos documentais, narrativos e de caso. Esse dado leva ao reconhecimento da importância e necessidade da realização de estudos pautados em uma maior diversificação metodológica acerca do ensino de Ciências integrado à formação cidadã, especialmente propondo alternativas de sua articulação que visem romper percepções simplistas sobre a cidadania e a superação das relações de dominação social (PINHÃO; MARTINS, 2016).

A diversificação metodológica das pesquisas pode ser uma via de superação da ausência de uma ação reflexiva no ensino de Ciências que considere a cidadania integrante do processo formativo do aluno. A adoção de estudos do tipo história oral, história de vida, pesquisa-ação e etnografia, dentre outros, pode oportunizar novos horizontes de saberes científicos e tecnológicos articulados à cidadania, o que também vai ao encontro da não saturação metodológica das pesquisas.

Ainda com relação ao aspecto metodológico das produções, seis foram desenvolvidas tomando como ponto de partida o professor de Ciências atuante na educação básica como interlocutor para a geração dos dados, uma utilizou documentos e outra apoiou-se em materiais didático-pedagógicos utilizados pelos professores em suas aulas. Foram utilizadas, com maior frequência, entrevistas e observações para a geração dos dados, sendo estes analisados, em geral, por intermédio da análise de conteúdo ou da análise textual discursiva.

Apresentados os aspectos mais gerais das produções analisadas, cabe discutir algumas características mais específicas que permitem identificar convergências e divergências quanto à exploração da questão em discussão. Para tanto, foram criadas três categorias indutivas visando agrupar os dados com base em suas aproximações e distanciamentos, isto é, "por um processo de comparar e contrastar constante entre as unidades de análise, o pesquisador organiza conjuntos de elementos semelhantes, geralmente com base em seu conhecimento tácito" (MORAES; GALIAZZI, 2016, p. 45).

Três produções assentam-se nas discussões sobre formação de professores de Ciências, seja inicial ou continuada, como um aspecto a ser levado em consideração na efetivação de um ensino de Ciências direcionado à formação cidadã, como é o caso de 
Camargo (2010), Silva (2013) e Silva (2014). Estes apresentam resultados de ações desenvolvidas junto a professores no intuito de oportunizar reflexões de ressignificação epistemológica que gerem novos modos de articular o ensino de Ciências com a formação cidadã.

Camargo (2010) investigou os dilemas enfrentados por professoras de escola pública quanto ao ensino de Ciências para a cidadania, tomada pela autora como uma história sagrada. Apoiando-se na pesquisa narrativa, foram feitas observações das aulas das professoras investigadas, além de entrevistas com as mesmas. Foi verificado que o contexto social que as professoras estão inseridas é incorporado aos seus dilemas e conhecimentos pessoais, reverberando no ensino de Ciências. O estudo parte da concepção de que o conhecimento curricular é relevante para a promoção e concretização de um ensino de Ciências para formar alunos cidadãos, porém defende maior protagonismo das práticas que permeiam as relações entre alunos, professores e demais sujeitos envolvidos nesse processo, enquanto história sagrada, para a construção do conhecimento científico.

O estudo de Silva (2013) teve como base os resultados obtidos em um curso de capacitação com professores dos anos iniciais do ensino fundamental de um município de Minas Gerais com a temática de Alfabetização Científica. Com base nessa formação, a autora selecionou alguns professores cursistas para incorporarem os conhecimentos dessa formação às suas práticas em sala de aula a partir da elaboração e aplicação de um planejamento pedagógico para suas turmas. Como resultados desse processo, verificou-se uma contribuição positiva dessa ação para o processo de ensino-aprendizagem, não se restringindo apenas ao momento proposto, mas sendo implantado durante o ano letivo investigado. $\mathrm{O}$ curso "possibilitou um olhar diferenciado para o ensino de Ciências com vistas à cidadania, na medida em que os conhecimentos podem colaborar no entendimento das questões do cotidiano, desde as mais simples até as mais complexas" (p. 6).

Silva (2014) investigou um curso de formação continuada de professores ofertado pelo autor em um município do Rio Grande do Sul para professores de Ciências da rede pública municipal. Apresentando elementos de uma pesquisa-ação, o estudo propôs tecnologias educacionais que oportunizassem uma aproximação entre os saberes e fazeres docentes para que houvesse um ensino de Ciências significativo e cidadão, o que, inicialmente, não foi bem aceito pelos professores, tendo em vista que parte destes seguia, à risca, as orientações e materiais de suas unidades de ensino. Contudo, a incorporação das ações do estudo contribuiu 
para reflexões e mudanças epistemológicas entre os professores para se pensar um ensino de Ciências para a cidadania.

Concorda-se que para pensar um ensino de Ciências para a cidadania deve ser considerado a formação docente como um elemento mantenedor desse processo, uma vez que a ação docente é a engrenagem do processo educativo. $O$ trabalho docente, dessa forma, demanda mecanismos teórico-metodológicos que oportunizem uma práxis efetiva e que vá ao encontro das necessidades socioformativas dos alunos. Se há uma educação científica e tecnológica destoante da realidade que o aluno está inserido, não oportunizando-o um desenvolvimento de pensamento crítico, participativo e emancipatório, (re)produz-se formas de exclusão e a manutenção da permanência na ignorância como sujeito passivo. Logo, em se tratando da formação docente continuada como aspecto mais expressivo nas produções analisadas, deve-se:

adotar o conceito de formação que privilegie a construção de conhecimentos e teorias sobre a prática docente, a partir da reflexão crítica, deixando de lado o conceito de formação docente como processo de atualização que em muitos momentos está descontextualizado da prática educativa do professor (SERRA, 2012, p. 26).

A abordagem Ciência-Tecnologia-Sociedade (CTS) para se pensar a formação cidadã no ensino de Ciências foi outra vertente adotada por algumas das produções. Tal abordagem, segundo Carneiro (1998), ganhou forças no Brasil na década de 1980 após discussões sobre o reconhecimento da não neutralidade e a responsabilidade da ciência para com a sociedade. A adoção da abordagem CTS no ensino de Ciências tem se popularizado no país, tornando-se necessário um aprofundamento quanto à essa realidade, já que se corre o risco, mesmo sob o discurso da tomada de decisões, de serem reproduzidos projetos curriculares autoritários e tecnocráticos, cuja participação social se dê apenas no final dos processos (AULER; DELIZOICOV, 2006; SANTOS; AULER, 2019).

Levando isso em consideração, para uma efetiva utilização da CTS no ensino de Ciências, Auler e Delizoicov (2006) defendem que o pensamento freiriano pode oportunizar um encontro efetivo entre o processo de escolarização e a leitura crítica da sociedade na qual o aluno está inserido, fortalecendo sua importância social e educacional. Desse modo,

Freire ajuda-nos a compreender que, para a constituição de uma cultura de participação, torna-se fundamental uma leitura crítica da realidade. Leitura crítica possibilitada por uma compreensão crítica das interações entre Ciência-TecnologiaSociedade - problematização e superação da suposta neutralidade - aspecto que encontra contribuições no campo CTS (SANTOS; AULER, 2019, p. 490). 
Das produções analisadas, podem ser inseridos nesse contexto os estudos de Oliveira (2013) e Matias (2014). Em seu estudo, Oliveira (2013) teve como ponto de partida o entendimento da abordagem CTS para a construção de um conhecimento científico crítico e colaborador para a formação cidadã na educação escolar. Analisando uma escola pública de ensino fundamental em Aracaju/SE, o autor investigou percepções de alunos quanto à ciência, seus professores e as aulas que eles ministram, bem como percepções dos próprios professores sobre o processo de ensino-aprendizagem a partir da aplicação de uma sequência didática.

Com ampla participação e aceitação da comunidade escolar quanto à proposta do autor, verificou-se que os professores carecem de aproximação teórico-metodológica com os princípios da interdisciplinaridade, especialmente quanto à ação-reflexão de sua prática pedagógica. Tais constatações fizeram com que a abordagem CTS não se concretizasse, de fato, na sequência didática proposta, limitando pensar a relação entre esse tripé e, consequentemente, as implicações da ciência e tecnologia para a sociedade.

Por sua vez, Matias (2014) buscou identificar a concepção de cidadania presente nos discursos de professores de Ciências atuantes nos anos finais do ensino fundamental e no ensino médio em uma região metropolitana do estado de São Paulo. O intuito do estudo era analisar como essas concepções reverberam na formação cidadã dos alunos. Através da realização de entrevistas, a autora constatou que são múltiplas as concepções de cidadania presentes no ideário dos professores entrevistados, mas havendo predominância da concepção de cidadania moderna. Quanto ao ensino de Ciências, foi verificada uma dificuldade entre os professores em articulá-lo à formação cidadã em virtude da concepção de cidadania que os mesmos possuem, sendo recomendado pela autora a discussão entre ciência e cidadania nos cursos de formação inicial e continuada. Essa formação poderá subsidiar a atuação do professor para que utilize a abordagem CTS para formar alunos cidadãos.

Uma terceira vertente que emergiu das teses e dissertações mapeadas diz respeito à análise de materiais didático-pedagógicos produzidos e/ou utilizados por professores de Ciências, tendo a formação cidadã como condutora dessa análise. Integram essa vertente os estudos de Gonçalves (2014), Santana (2015) e Valdez (2017). Desse modo, Gonçalves (2014) investigou as características teóricas e metodológicas que emergem das práticas educativas presentes nas produções científicas brasileiras, espanholas e portuguesas em um evento ibero-americano de CTS. A análise das produções mostrou que essas estão assentadas 
em três vertentes: pensamento freiriano, axiologia e interdisciplinaridade. As produções possuem relatos de intervenções didáticas com alunos da educação básica pautada no debate crítico e efetiva participação dos alunos, conduzindo-os para uma formação cidadã e participativa com base em conhecimentos científicos e tecnológicos, isto é, para a tomada de decisões.

Em Santana (2015), o estudo tem como ponto de partida o material didático utilizado por professores e alunos no Projovem Urbano, buscando analisar o discurso sobre Ciências da Natureza e sua relação com a formação cidadã presente nesse material, já que uma parte considerável dos alunos que utiliza esse material encontra-se em situação de desigualdade/vulnerabilidade social. A autora constatou que o material, considerando o contexto social dos alunos que o utilizam, contribui para a construção de um conhecimento científico condizente com as demandas da participação social, agregando um pensamento crítico para que possam reconhecer-se enquanto sujeitos socialmente desiguais e, com isso, buscarem transformar a realidade que estão inseridos.

Por fim, Valdez (2017) desenvolveu uma matriz de competências e habilidades voltada ao ensino de Ciências considerando a investigação científica com o intuito de contribuir para a prática pedagógica dos professores de qualquer área do conhecimento que desejem se debruçar sobre a formação cidadã.

\footnotetext{
"A matriz proposta, denominada MEI, se apoia nos aspectos da investigação científica para que professores de qualquer área possam desenvolver, junto a seus alunos, competências e habilidades úteis para a formação cidadã, autonomia e sucesso em exames vestibulares" (p. 4).
}

A preocupação com o aporte teórico balizador da ação docente e dos materiais didáticos utilizados pelos alunos é um elemento que merece destaque nas pesquisas sobre o ensino de Ciências para a cidadania, já que, considerando tal feito, deve-se levar em conta o processo de ensino-aprendizagem como um ato político mediado por interações diversas. $\mathrm{Ou}$ seja, possibilitar a estes atores (mediadores e aprendizes) materiais discursivos que gerem reflexões e debates sobre a temática representa uma ação importante. As produções analisadas surgem nessa direção, mas compreendendo que esses materiais não devem ser a única fonte de conhecimento científico a ser adotado pelo professor nem pelo aluno, embora em muitos casos seja esta a realidade, fazendo com que se revele a importância de uma análise crítica desses materiais. 
As pesquisas analisadas apresentam apontamentos que dialogam entre si quanto à inserção do ensino de Ciências nas discussões sobre formação cidadã do aluno, uma vez que estas não devem ser centradas apenas no campo das Ciências Humanas, como comumente é percebido na educação. Pautar os conhecimentos científicos e tecnológicos nesse contexto é oportunizar maior criticidade ao aluno em formação, de modo que, aliado aos conhecimentos de outros campos, possa atuar como um agente de transformação na sociedade, modificando-a para melhor.

Pautar a perspectiva cidadã no ensino de Ciências envolve uma diversidade mais ampla de conhecimentos do que no ensino de Ciências tradicional e desvinculado desse elemento. Conduzir uma formação científica e tecnológica cidadã:

\footnotetext{
engloba conhecimentos relativos à filosofia e história da ciência; a linguagem científica, o conhecimento dos conceitos científicos e sua linguagem; e os aspectos sociocientíficos, conteúdos de natureza social, política, econômica, cultural, histórica, ambiental e ética vinculados à ciência e à tecnologia. Deve-se destacar que a educação científica engloba além desses conhecimentos valores (SANTOS, 2012, p. 57-58).
}

Em suma, a proposta da construção de um mapeamento de teses e dissertações via EQ mostrou a necessidade da expansão não apenas da produção científica dessa temática, mas também de sua materialização na sala de aula, pois entende-se que se há baixa produção acadêmica sobre, pode-se inferir que também há baixa materialização dessa relação ciênciacidadania na sala de aula, gerando-se menos possibilidade de formar alunos, de fato, cidadãos com conhecimentos científicos e tecnológicos para uma tomada de decisão coerente com cada realidade.

\section{O que tudo isso indica?}

O estado da questão contribui para a construção de pesquisas acadêmicas ao apresentar, de forma estruturada, como determinado assunto tem sido abordado nas pesquisas científicas em um dado contexto e período. Identifica o que há ou não de novo sobre o assunto de interesse não apenas na abordagem teórica, mas também metodológica e em outros aspectos da pesquisa científica. Traz à tona a diversidade de produções sobre um tema a partir de olhares múltiplos, indicando ou não a saturação dessa produção.

O mapeamento construído revelou que a formação cidadã tem sido pautada nas pesquisas que tratam do ensino de Ciências em teses e dissertações de universidades públicas brasileiras. No entanto, há uma má distribuição geográfica destas pesquisas no país, havendo 
predominância na região Sudeste. Ainda que a formação cidadã tenha sido instituída pela LDB como uma finalidade da educação básica em 1996, só foram encontradas produções a partir de 2010, isto é, mais de uma década depois.

Os direcionamentos dados às e pelas produções são diversas, contemplando uma diversificação teórico-metodológica, mas que encaminham o leitor para o entendimento de que as discussões sobre formação cidadã no currículo escolar devem superar sua centralização apenas nas áreas de Ciências Humanas e/ou Sociais, cujo campo das Ciências Naturais, por exemplo, também pode e deve subsidiar o fomento à cidadania a partir dos conhecimentos científicos e tecnológicos que impactam diretamente na sociedade, em todos os seus setores.

Dessa forma, pensar um ensino de Ciências na perspectiva da formação cidadã requer uma interlocução entre diversos campos, configurando-se como um processo interdisciplinar e que engloba desde o material didático utilizado por professores e alunos até a formação continuada docente. Assim, este mapeamento revela a importância de se discutir esta temática, bem como ampliá-la a fim de que a educação científica e tecnológica não ocorra de forma neutra, mas pautada em uma abordagem social e crítica.

\section{Agradecimentos}

À Fundação Cearense de Apoio ao Desenvolvimento Científico e Tecnológico (FUNCAP), pela concessão da bolsa de mestrado ao primeiro autor.

\section{Referências}

AULER, D.; DELIZOICOV, D. Ciência-Tecnologia-Sociedade: relações estabelecidas por professores de ciências. Revista Eletrónica de Enseñanza de Las Ciências, Vigo, v. 5, n. 2, p. 337-355, 2006.

CAMARGO, C. C. Dilemas vividos por duas professoras da escola pública ao ensinarem Ciências em uma perspectiva de formação para a cidadania. 2010. Tese (Doutorado em Educação) - Centro de Educação e Ciências Humanas, Universidade Federal de São Carlos, São Carlos, 2010.

CARNEIRO, C. C. B. S. Currículo de Ciências: história, concepções e opções. 1998. Tese (Doutorado em Educação) - Faculdade de Educação, Universidade Federal do Ceará, Fortaleza, 1998.

CHASSOT, A. I. Da Química às Ciências: um caminho ao avesso. In: ROSA, M. I. P.; ROSSI, A. V. (org.). Educação Química no Brasil: memórias, políticas e tendências. 2. ed. Campinas: Editora Átomo, 2012. 
CHASSOT, A. I. Desafios de ser professor hoje. R. de Ciências Humanas, Frederico Westphalen, v. 12, n. 19, p. 11-28, 2011.

CHIARINI, T.; VIEIRA, K. P. Universidades como produtoras de conhecimento para o desenvolvimento econômico: sistema superior de ensino e as políticas de CT\&I. Rev. Bras. Econ., Rio de Janeiro, v. 66, n. 1, p. 117-132, jan./mar. 2012.

GADOTTI, M. Concepção dialética da educação: um estudo introdutório. 15. ed. São Paulo: Cortez, 2006.

GONÇALVES, R. S. Projetos temáticos e enfoque CTS na educação básica: caracterização dos trabalhos apresentados por autores brasileiros, espanhóis e portugueses nos seminários ibero-americanos de CTS. 2014. Dissertação (Mestrado profissional em Ensino de Ciências) Universidade Federal de Itajubá, Itajubá, 2014.

MATIAS, L. Análise interpretativa de relatos de professores de Ciências sobre o tema cidadania. 2014. Dissertação (Mestrado em Ensino, História e Filosofia das Ciências e da Matemática) - Universidade Federal do ABC, Santo André, 2014.

MORAES, R.; GALIAZZI, M. C. Análise Textual Discursiva. 3. ed. Ijuí: Ed. Unijuí, 2016.

NÓBREGA-THERRIEN, S. M.; THERRIEN, J. O estado da questão: aportes teóricometodológicos e relatos de sua produção em trabalhos científicos. In: FARIAS, I. M. S.; NUNES, J. B. C.; NÓBREGA-THERRIEN, S. M. (org.). Pesquisa científica para iniciantes: caminhando no labirinto. Fortaleza: EdUECE, 2010. p. 33-52.

OLIVEIRA, T. B. Ensino de Ciências na perspectiva CTS - concepções e práticas escolares. 2013. Dissertação (Mestrado em Ensino de Ciências Naturais e Matemática) - Universidade Federal de Sergipe, São Cristóvão, 2013.

PINHÃO, F.; MARTINS, I. Cidadania e ensino de Ciências: questões para o debate. Revista Ensaio, Belo Horizonte, v. 18, n. 3, p. 9-29, set./dez, 2016.

SANTANA, C. B. A. Ciências da natureza no projovem urbano: discursos de um currículo inventado e praticado. 2015. Dissertação (Mestrado em Educação) - Departamento de Educação, Universidade Estadual de Feira de Santana, Feira de Santana, 2015.

SANTOS, R. A.; AULER, D. Práticas educativas CTS: busca de uma participação social para além da avaliação de impactos da Ciência-Tecnologia na Sociedade. Ciênc. Educ., Bauru, v. 25, n. 2, p. 485-503, 2019.

SANTOS, W. L. P. Educação científica na perspectiva de letramento como prática social: funções, princípios e desafios. Revista Brasileira de Educação, Rio de Janeiro, v. 12, n. 36, p. 474-492, set./dez. 2007.

SANTOS, W. L. P. Educação CTS e cidadania: confluências e diferenças. Amazônia: Revista de Educação em Ciências e Matemáticas, Belém, v. 9, n. 17, p. 49-62, 2012.

SERRA, H. Formação de professores e formação para o ensino de Ciências. Educação $e$ Fronteiras On-Line, Dourados, v. 2, n. 6, p. 24-36, set./dez. 2012.

SIDONE, O. J. G.; HADDAD, E. A.; MENA-CHALCO, J. P. A ciência nas regiões brasileiras: evolução da produção e das redes de colaboração científica. Transinformação, Campinas, v. 28, n. 1, p. 15-32, 2016. 
SILVA, A. L. S. A formação de um professor de Ciências pesquisador a partir de seu saber/fazer pedagógico. 2014. Tese (Doutorado em Educação em Ciências: Química da Vida e da Saúde) - Instituto de Ciências Básicas e da Saúde, Universidade Federal do Rio Grande do Sul, Porto Alegre, 2014.

SILVA, M. L. P. Alfabetização científica nos anos iniciais do ensino fundamental na rede municipal de Piranguçu/MG: formação e prática. 2013. Dissertação (Mestrado profissional em Ensino de Ciências) - Universidade Federal de Itajubá, Itajubá, 2013.

SILVA, R. M. G. Ensino de Ciências e Cidadania. In: SCHNETZLER, R. P.; ARAGÃO, R. M. R. Ensino de Ciências: fundamento e abordagens. Piracicaba: Capes/Unimep, 2000.

SILVA, W. D. A.; CARNEIRO, C.C. B. S. Quando o social indaga sobre a ciência: o ensino de Química e o direito de o aluno saber-se socialmente desigual. In: ENCONTRO NACIONAL DE PESQUISA EM EDUCAÇÃO EM CIÊNCIAS, 12., 2019, Natal. Anais [...]. Natal: ABRAPEC, 2019. p.1-7.

VALDEZ, V. R. Desenvolvimento de uma matriz de competências e habilidades para repensar o ensino de Ciências pela perspectiva do ensino por investigação. 2017. Dissertação (Mestrado profissional em Ensino de Ciências) - Universidade de Brasília, Brasília, 2017. 